\title{
Towards Spatially Explicit Agent-based Model for Simulation of Informal Transport Infrastructure Indirect Growth Dynamic in Informal Settlements
}

\author{
H.Vahidi ${ }^{\text {a, b* }}$, W.Yan ${ }^{\text {a, c }}$ \\ ${ }^{a}$ Graduate School of Media and Governance, Shonan Fujisawa Campus, Keio University, Fujisawa-shi, Japan - \\ (vahidi, yan)@sfc.keio.ac.jp \\ ${ }^{\mathrm{b}}$ Global Environmental System Leaders Program, Shonan Fujisawa Campus, Keio University, Fujisawa-shi, Japan \\ ${ }^{\mathrm{c}}$ Faculty of Environmental and Information Studies, Shonan Fujisawa Campus, Keio University, Fujisawa-shi, Japan
} KEY WORDS: Informal Settlement, Transport Infrastructure, Road and Footpath, Agent-based Modelling, Simulation, Extension
Dynamic

\begin{abstract}
:
The informal construction of dwellings (housing) and the informal growth of transport infrastructure are two main dynamics of an informal settlement growth phenomenon that may influence each other over time. Some studies have been done to understand the growth mechanisms of informal settlements, but not enough attention has been paid to study the informal growth of transport infrastructure dynamic. In this study, the morphology and spatial pattern of different types of informal settlements have been reviewed and categorized to clearly define and formulate the mechanisms of informal transport infrastructure formation in the context of informal settlement. To this end, two different dynamics have been suggested in this study for modelling of the growth of informal transport infrastructure. In the first suggested dynamic, the infrastructure is extended directly as the result of consolidation of the physical signs of dwellers' movement (foot prints) on the environment over time. In the second proposed dynamic that is the main focus of this study, the informal infrastructure growth could be considered as the function of dwelling construction (housing) dynamic in the settlement. In this context, informal transport infrastructure is extended based on an indirect dynamic by consideration of the void spaces by dwellers as the accessibility corridors in the settlement during the construction process of the settlement. Finally, to study the validity of the second proposed dynamic for modelling of the indirect growth of informal transport infrastructure, a simple conceptual model was developed and tested and the results were evaluated and discussed.
\end{abstract}

\section{INTRODUCTION}

Informal settlements (slums) are rapid and unplanned developing regions which are suffering severely from the lack of legal supervision. Development of informal settlements lead to increase of poverty, inequality and social exclusion in the major cities of developing countries (Sietchiping, 2005). Increased knowledge about the factors that influence the growth of these settlements as well as their impact mechanisms, may help responsible authorities to manage and plan for future facilities (such as health care, water supplying systems, pipelines and electrical transmission lines) within the settlement and prepare the effective social, economical and physical plans for direct or indirect control of urban growth direction.

Urban system of informal settlement includes two main components: buildings and transport infrastructure (roads and footpaths).

As the urban system has a complex dynamic nature these components influence each other over time. According to Sliuzas (1988) study, informal settlement occurs mainly along infrastructures. In some conditions, the growth in informal transport infrastructure may affect the pattern of informal construction in the informal settlement and it can cause the construction of new buildings around the expanded infrastructure. Also, it could be expected that the new constructed buildings cause the generation of new trips in the area which may lead to a new phase of informal transport infrastructure growth.
Informal Infrastructure (informal transport infrastructure) undertakes the role of connection between significant destinations as well as providing the accessibility of zones and facilities for both human and vehicles in the area. Therefore, understanding and formulating the growth dynamic of informal infrastructure is a necessary task.

Simulation models can help to investigate the factors that influence the dwelling and infrastructure growth and gain a better understanding from the existing trade-offs between dwelling growth and the infrastructure growth in the context of informal settlement expansion.

To model and simulation the growth of informal settlement in a realistic way, it is needed to have a concrete realistic submodels for simulation of dwelling and informal infrastructure growth in the context of informal settlement.

Yamins, et al. (2003) study indicates that little attention has been paid to modeling of transportation infrastructure growth by researchers in comparison to dwelling growth modelling. Up to now, several models have been developed for simulation of infrastructure growth process. Hence, more attention is needed to understand the dynamics of informal infrastructure formation and to formulate a comprehensive realistic model for simulation of informal growth of infrastructure in the context of informal settlement.

Huang \& Levinson (2009) divided infrastructure growth models in to three main categories: probabilistic network growths models, network design models and agent-based models.

Majority of the models in the first and second category, have a top-down nature and suitable for simulation of formal

\footnotetext{
* Corresponding author.
} 
infrastructure growth dynamic. In addition, most of these models are at the macro scale levels which do not provide the ability of study of the growth dynamic at the micro scale level. Agent-based simulation models have a bottom-up and individual based nature, therefore it is suitable for simulation of the growth process in infrastructure as a result of different behaviours of the settlers. This modelling approach can consider the heterogeneity of agents (different types of settlers) and different behaviour of them in the interaction with each other and with the environment.

Previous agent-based models for simulation of infrastructure growth mostly concentrated on the modelling of planned and structured settlements. So, the existing agent-based models cannot fully handle the simulation of the informal growth of infrastructure in the context of informal settlements.

To address the above-mentioned research gap, this paper is structured as the following: In the next section we will review and categorize the different types of the settlement growth in the context of informal settlement. Latter, two different dynamics will be suggested for modelling of the informal transport infrastructure growth in the informal settlements. In the section 4 , a prototype model will be implemented to study the indirect growth dynamic of informal infrastructure and the result of this study will be disused. The paper is finished in section 5 with conclusion remarks and some tips for future research directions.

\section{EXPLORING THE GEOMETRY AND MORPHOLOGY OF INFORMAL SETTLEMENTS}

In the absence of enough fine scale spatio-temporal, social and economical data on the initial state of the informal settlement system and during the time-span of the informal settlement formation, most of the existing studies that focus on selforganizing mechanisms in the process of informal settlements formation are limited to study or simulation of the dynamics and emergent spatio-temporal patterns of informal settlement at scale of neighbourhood or district or coarser spatial scales.

To our knowledge, up to now a few studies have been done to study or simulate the self-organizing mechanisms in the context of informal settlement and emergent spatio-temporal patterns in the formation of informal settlement at fine scale level. However, the existing fine scale studies in this context have been limited to a few particular case studies and not enough attention has been paid to develop a holistic global model for understanding of mechanisms and emergent patterns in the formation process of informal settlement.

Nevertheless, in the following paragraphs we will review the few existing fine scale studies to get an overview about the emergent spatial and temporal patterns in the formation of informal settlement to develop our model for simulation of informal infrastructure growth based on the obtained insight in the following sections.

The geometry of informal settlement usually emerged as the result of an irregular distribution of different islands or groups of the informal houses and because of this, they have usually considered in the past as disordered, non-logical structures and therefore impossible to fully understand and model (Sobreira \& Gomes, 2001).

Rapoport (1988) argued that the informal settlements as spontaneous structures, same as all other human-made environments, do not just flourished accidently but they are formed as the result of purposeful changes (based on the different physical, social and economical factors) in the environment based a series of choices from the available alternatives.
Sobreira and Gomes (2001) conducted a study on the geometry of several informal settlements in Brazil and Kenya to investigate whether the apparent disordered and irregular spatial patterns in the context of informal settlements can be understood and explained if they have been interpreted in the term of the complex system (Figure 1). In their study they only focused on studying of the role of transport infrastructure and physical barriers on the geometry of the informal settlement and the role of other physical, social and economical factors were not considered.

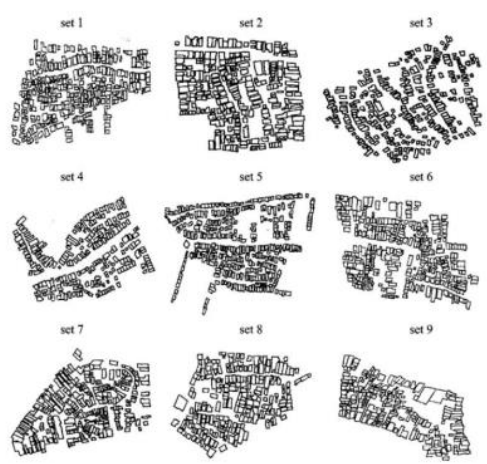

Figure 1. Map of Nine Informal Settlements, Recife Region, Brazil (Sobreira \& Gomes, 2001)

To this end, they studied the emergent spatial patterns in the structure of informal settlements in the context fragmented structures (i.e. island of dwellings) and void spaces between the dwellings (Figure 2).

Their observations from the emergent spatial patterns in the investigated case studies in Brazil indicated that there are a large number of small islands in each settlement and a few number of large fragments in the studied systems. Furthermore, they mentioned that all of the studied case studies in Brazil were embedded in urban body and the majority of these structures adhere to the settlement's rigid boundary conditions.

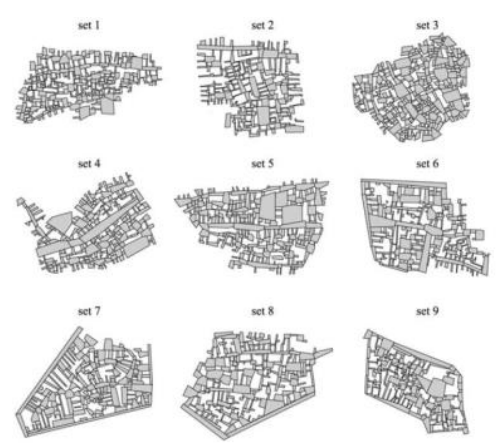

Figure 2. Covering of the Void Spaces of Nine Informal Settlements, Recife Region, Brazil (Sobreira \& Gomes, 2001)

They claimed that when there are no rigid boundaries (e.g. road, rail road, river etc.) to spatially limit the growth of informal settlement at its extents, the settlement spreads in the neighbourhood in a diffusion-like process and dwellings are distributed in a low-density and disordered way and form the islands of isolated dwellings (Figure $3 \mathrm{~A}$ ).

In contrast, their findings showed that when an informal settlement is fully surrounded by the rigid boundaries, the 
formation of the settlement occurs in a kind of packing-like process and the dwellings spread in the area in an ordered way (Figure $3 \mathrm{~B}$ ).

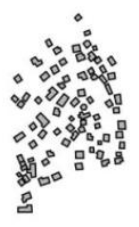

A

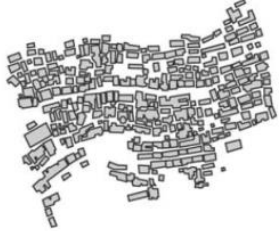

B
Figure 3. A: Diffusion-like Settlement Formation Process, B: Packing-like Settlement Formation Process (Sobreira \& Gomes, 2001)

They expressed that as this category of informal settlements has a closed system, by construction of the new buildings in the area, the densification rate of the settlement increases. Hence, in a closed high density settlement, every new added dwelling to the system must adhere to constraints which posed by spatial availability. In this term, they argued that if the size of all dwelling islands is at minimum value (i.e. we have the isolated dwelling islands with the size 1 in the system), the system has more void spaces and lower density but the occupancy in the limited space of the settlement would be not optimized. In contrast, if the settlement configuration is composed of a small number of large dwelling islands, the area of void spaces in the system is lower and density would be considerably higher. However, the output pattern of occupancy would not provide the minimum requirements for providing of dwelling's access and privacy as there are not enough void spaces in the area. Therefore, this configuration also would be a non-optimized pattern for informal settlement growth in the bounded neighbourhoods.

Sobreira and Gomes (2001) stated that the emergent diversity in the context of the size of dwelling islands in the spatial pattern of strictly bounded informal settlements is formed based on a decentralized optimizing dynamic in the complex system of informal settlement to optimize the process of occupation of the free spaces in the system.

Although, it is not possible to find two informal settlements with exactly the same spatial configuration as the result of diversity in the environmental, social and economical characteristics of the different settlements, but some similarities might be found in the large-scale emerged spatial patterns (urban form) and layout of informal settlements.

Fernandez (2011) categorized the different types of observable settlement's spatial pattern in the context of informal settlements. However, we believe that some of the introduced types in her study could be considered as the special cases of some major categories. In addition, some of the main observable types of settlement's spatial pattern in the context of informal settlements have not considered in her list. To this end, the major types of observable settlement's spatial pattern in informal settlements have been reviewed again in this study and classified into 4 main categories (excluding the low-density dispersed housing pattern) (Table 1, Figure 4). However, sometimes more than one spatial pattern may affect the settlement's spatial pattern (i.e. a combination of the abovementioned 4 main settlement's spatial patterns might be observed in the informal settlement).

\begin{tabular}{|c|c|}
\hline $\begin{array}{c}\text { Structure and } \\
\text { Form }\end{array}$ & Main Characteristics \\
\hline $\begin{array}{c}\text { Informal } \\
\text { Settlement with }\end{array}$ & $\begin{array}{c}\text { Form of Urban Grid: Almost with Regular Grid } \\
\text { or Checkerboard (Orthogonal Framed Occupation }\end{array}$ \\
\hline
\end{tabular}

\begin{tabular}{|c|c|}
\hline Regular Grid & $\begin{array}{l}\text { Pattern } \\
\text { Transport Network: Parallel and Transversal with } \\
\text { an Almost Uniform Dimensions } \\
\text { Spatial Pattern Generator: Adopting or Imitating } \\
\text { of the Planned Settlement Pattern Based on a Top- } \\
\text { down or Bottom-up Factor }\end{array}$ \\
\hline $\begin{array}{l}\text { Transport } \\
\text { Infrastructure } \\
\text { Pattern } \\
\text { Adopted } \\
\text { Informal } \\
\text { Settlement }\end{array}$ & $\begin{array}{l}\text { Form of Urban Grid: Mostly Irregular (Deformed } \\
\text { Grid) } \\
\text { Transport Network: Irregular Network with Non- } \\
\text { uniform Dimensions } \\
\text { Spatial Pattern Generator: Aligning the houses } \\
\text { to the existed formal or informal transport } \\
\text { infrastructure (road or footpath) } \\
\text { Other Linear Features (e.g. River etc.) May } \\
\text { Have a Same Function as Transport } \\
\text { Infrastructure on Forming the Pattern of the } \\
\text { Settlement }\end{array}$ \\
\hline $\begin{array}{c}\text { Informal } \\
\text { Settlement } \\
\text { With } \\
\text { Concentric } \\
\text { Circular } \\
\text { Pattern Around } \\
\text { the Utilities or } \\
\text { Urban Features } \\
\end{array}$ & $\begin{array}{l}\text { Form of Urban Grid: Mostly Irregular (Deformed } \\
\text { Grid) } \\
\text { Transport Network: Irregular Network with Non- } \\
\text { uniform Dimensions } \\
\text { Spatial Pattern Generator: Construction of the } \\
\text { Houses Around the Important Utilities and Urban } \\
\text { Features (e.g. Religious Place, Water Well etc.) }\end{array}$ \\
\hline $\begin{array}{c}\text { Terrain } \\
\text { Topography } \\
\text { Adopted } \\
\text { Informal } \\
\text { Settlement }\end{array}$ & $\begin{array}{l}\text { Form of Urban Grid: Irregular (Deformed Grid) } \\
\text { Transport Network: Complex Network with } \\
\text { Usually Narrow and Tortuous Paths in a } \\
\text { Labyrinthine Structure } \\
\text { Spatial Pattern Generator: Construction of the } \\
\text { Houses Parallel to the Contour Lines to Adopt the } \\
\text { Topography of the Land Smoothly } \\
\text { If the Main Access to the Informal Settlement } \\
\text { Is Composed of the Perpendicular Paths to the } \\
\text { Contour Lines, a Radial Pattern Might be } \\
\text { Emerged in the Settlement }\end{array}$ \\
\hline
\end{tabular}

Table 1. Major Emergent Settlement's Spatial Patterns in the Context of Informal Settlements

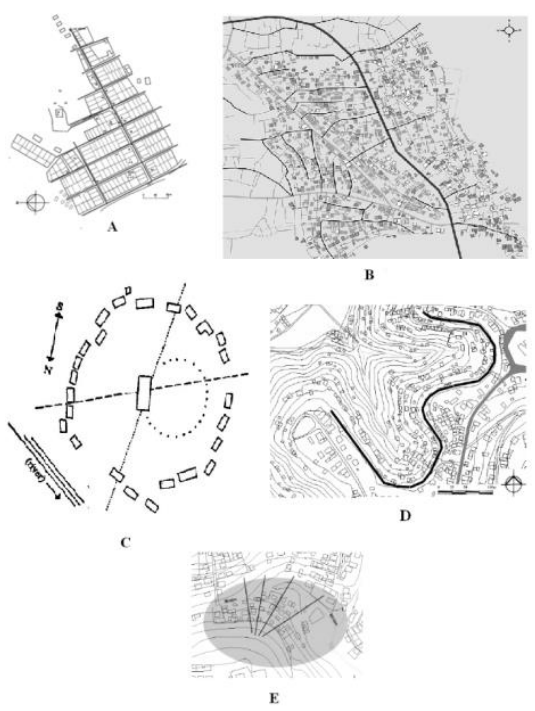

Figure 4. Examples of Major Emergent Settlement's Spatial Patterns in Informal Settlement: A: Informal Settlement with Regular Grid (Matos Mar, 1977), B: Transport Infrastructure Pattern Adopted Informal Settlement (Vahidi, 2010), C: Informal Settlement With Concentric Circular Pattern Around the Utilities or Urban Features (Kuilman, 2011), D: Terrain Topography Adopted Informal Settlement (CONDER, 2002); E: Terrain Topography Adopted Informal Settlement (CONDER, 2002); (Fernandez, 2011) 
As the different physical and social factors usually affected the pattern and orientation of housing at the different locations in the informal settlement, no global order might be seen in the settlement. But, in the most cases a global order might be observed in the scale of each fragment. In this sense, the first settlers in the fragment construct their houses based on one of the several settlement's spatial patterns (refer to Table 1), and the newcomers mostly adhere to the accepted pattern in the fragment and build the new houses with the same plan adjacent to the first houses in the fragment. Over time, the new settlers who determined to construct their houses in the backside of the first row of houses in the fragment usually try to align their houses parallel to the houses in the first row and so on. This goal-oriented self-ordering behaviour is formed in a collective approach by the dwellers to optimize the occupancy pattern of the fragment.

\section{DEVELOPING A FRAMEWORK FOR MODELLING OF INFORMAL TRANSPORT INFRASTRUCTURE GROWTH IN THE CONTEXT OF INFORMAL SETTLEMENTS}

In the previous section, the emerged spatial pattern and morphology of the informal settlements have been studied in detail. This study showed if the exceptional low-density dispersed housing pattern is excluded, generally it could be observed that usually some degrees of order might be seen in the settlement spatial pattern of informal settlement in the fragment level. In this context, to develop a framework for modelling of the growth of informal transport infrastructure in informal settlements, two different dynamics have been identified in this study. The basic concepts of this new taxonomy will be proposed in this study to ensure that the different dynamics in the formation of informal transport infrastructure precisely differentiated and considered. In this term, indirect growth dynamic and direct growth dynamic will be proposed as two effective dynamics in the formation of informal transport infrastructure in informal settlements and will be discussed in the following sections.

\subsection{Direct Dynamic of Informal Transport Infrastructure Growth}

Direct dynamic of informal transport infrastructure (trail system) formation from an origin to a destination has a bottomup nature. Basically, this process starts when a track is created by a single settler in the form of physical signs such as the compacted ground or damaged and trampled vegetation. This track will be developed into a footpath if it has been used frequently by many people.

Bottom-up process of direct growth in infrastructure system is initiated from the different daily behaviours of settlers and is influenced by various social, economical and physical factors.

This dynamic of trail formation is basically the predominant dynamic of path formation between origins and destinations in the informal settlements, however during the middle stages of extension stage in informal settlement (construction of new houses in the open space of the settlement) and latter during densification (infilling) stage of formation and growth of the informal settlements, most of these trails will be disappeared. In this context, the buildings would be built on the track of footpath if that footpath has used only by a few number of dwellers and not consolidated enough in the settlement. Therefore, at the middle stages of extension dynamic and at the beginning of informal settlement densification stage in the growth process of informal settlements, mostly the considered void spaces by the dwellers between the dwellings will take the burden of channelizing and addressing the daily trips in the settlement (for more details see section 3.2).

Consequently, in the informal settlements with dense and bounded configuration and rapid rate of growth, the direct dynamic of informal transport infrastructure formation might be neglected (if only we need to model and simulate the final pattern of infrastructure system and final spatial pattern of the settlement) in the most cases, as usually they do not have a considerable effect on the final emergent spatial pattern of informal infrastructure and the spatial pattern of informal settlement.

However, in some exceptional cases, the direct dynamic of informal transport infrastructure formation may considerably affect the final emergent spatial pattern of informal infrastructure and the spatial pattern of informal settlement.

In first type of these exceptional cases, the informal infrastructure is formed between the informal settlement to a common destination between the different dwellers (such as water well, formal road etc.) located outside of the current extent of the settlement. In this context, if the informal path has been used frequently by the different dwellers frequently, the formed trail has a chance to be consolidated over time. In this sense, a well consolidated trail has a high chance to be recognized by the newcomers as a major path that should be preserved in the horizontal growth stage of informal settlement (Figure 5). This type of informal transport infrastructure can have effective impact on the future direction of horizontal growth of informal settlement and as therefore the spatial pattern of informal settlement as the newcomers usually interested to construct their houses adjacent to the consolidated paths.

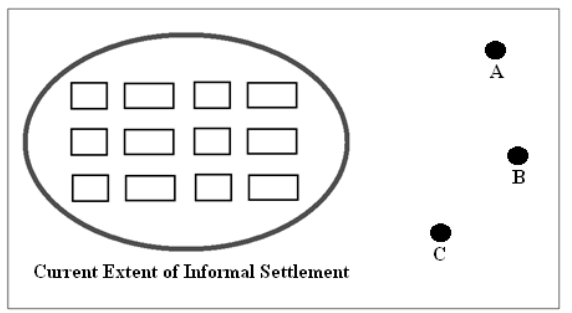

Figure 5. Common Destinations that Placed Outside of Current Extent of the Informal Settlement

In addition to this, an informal infrastructure that is emerged based on the direct dynamic also might be preserved in the informal settlement with a dispersed pattern or in the settlement with an slow growth rate if the path is frequently used by several dwellers overtime and the trail would find the chance to be consolidated enough and to be recognized as a major path before the construction of new dwellings over the free space.

To develop an agent-based model for simulation of direct growth dynamic of informal transport infrastructure, the concepts of the previous studies by Helbing, et al.(1997) and Goldstone and Roberts (2006) for modelling of informal trail formation in the natural landscape can be adopted to develop a more realistic model in the case of informal settlements.

\subsection{Indirect Dynamic of Informal Transport Infrastructure Growth}

This dynamic mainly is observed in the settlements with almost ordered settlement's spatial pattern (with non-dispersal spatial pattern) in the fragment level which have bounded extents with a fast extension and densification dynamic. For modelling of 
the final pattern of informal transport infrastructure in this type of settlements, the formation of informal transport infrastructure could be considered as the function of settlement construction (housing) dynamic. Based on this definition, when a settler constructs his/her house (according to his/her adopted pattern of housing) in the first row of fragment, usually he/she considers a void space (as a path) parallel to his/her house and this trend has been adapted by other new dwellers in the first row of houses construction in the fragment. This system also adopted by the next settlers at the next row of construction in the fragment and so on and in this sense the transport infrastructure is indirectly developed and penetrates between the houses in the term of void spaces to provide the accessibility of building blocks. For connection of two parallel contiguous building rows (or dwellings) and providing the basic or secondary accessibility of them, usually, the void space (s) has (have) been considered between two rows by the dwellers in the appropriate distance(s).

To our knowledge, in the context of fine-scale modelling of the informal settlement growth, up to now, only two research have been conducted by Iqbal (2009) and Augustijn-Beckers, et al. (2011). In both of these proposed models, the spatial pattern of informal infrastructure was fully adopted from the final state of transport informal infrastructure in the reality. Therefore, for the means of simplification, they assumed that the informal infrastructure has a static nature and fully existed in the area at the beginning of simulation, therefore they only concentrated on developing a model for fine-scale simulation housing (extension and infilling dynamics).

In this context, we suggest that the current existing fine-scale housing models can be developed by a sub-model for modelling of the indirect informal infrastructure growth pattern (in the context of creating the void spaces in the settlement) to improve the current settlement growth models by considering the realistic behavioural rules of dwellers in the indirect formation informal transport infrastructure.

\section{A PROTOTYPE MODEL FOR INITIAL TESTING OF POROPOSED MODEL FOR INDIRECT DYNAMIC OF INFORMAL TRASNPORT INFRASTRACTURE GROWTH}

It was mentioned that the indirect growth dynamic of informal transport infrastructure could be considered as a sub-dynamic of informal housing dynamic. As the existing developed models for simulation of the informal settlement growth are not available for us, so in the absence of these implemented models, a simple and limited agent-based model has been developed and implemented as a prototype to model the housing mechanism in the context of informal settlement in order to test the validity of the proposed dynamic for the indirect growth of informal transport infrastructure. In the following sections, first we will introduce our case study and briefly review the proposed prototype model and finally the result of the implemented prototype will be illustrated and discussed.

\subsection{Case Study}

A part of Manzese informal settlement in Dar es Salaam, Tanzania was selected as a case study for implementing the proposed prototype model (Figure 6). The formation of this informal settlement is back to 1967 and continued until the early 1990s. However, the main extension and infilling of the settlement has been done between 1967-1982 (AugustijnBeckers, et al., 2011; R. Sliuzas, 2004)

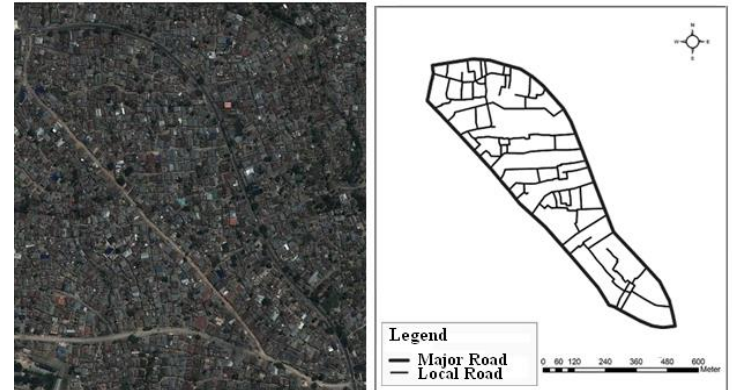

Figure 6. Satellite Image (Left), Transport Infrastructure Map (Right); Manzese, Dar es Salaam, Tanzania

This area was selected in our study as this neighbourhood has been studied extensively in the past by the different researchers, particularly by Iqbal (2009) and Augustijn-Beckers, et al. (2011) to implement their proposed models for simulation of the informal settlement growth phenomenon.

\subsection{Framework of Proposed Prototype Model}

In this simple agent-based prototype model, in each step (tick), a new point as a new house is generated randomly in one of the centroids of the houses that were constructed in the time frame of 1967-1982 to simulate the housing dynamic in a simple way. In this context the new house will be added in the study area at each stage of the simulation. In this study, it was assumed that at the initial state of study only the major formal (or upgraded) roads are existed in the area. To simulate the indirect mechanism of informal transport infrastructure (local roads) formation, it was assumed that every new constructed house considers a reserved void space (i.e. corridor) to provide it's accessibility to the existing infrastructure at each step. In this context, the centreline of the least cost corridor from the house centroid to the existing infrastructure in the settlement is created as a polyline and added to the network of informal infrastructure. To make a cost surface, the following issues have been considered: The steep slopes, physical obstacles and barriers in the area were considered as very high cost areas in the model's environment. As the corridors could not be passed and extended on the physical obstacles (e.g. buildings, river, swamp etc.), at the end of each tick, the generated point is converted to a $10 * 10$ cell as a physical obstacle and it is considered as a high cost area (insurmountable area) in the model's environment.

When it is possible, human prefers to walk on the land with a lower land slope ranges. To consider this fact, the topography of environment in the study area was categorized in to three cost categories (low, medium, high) based on the suggested ranges by Vahidi (2010) according to dwellers' preference in this study area.

Finally, for production of the final cost layer, the simulation environment was reclassified into three cost categories according the cost layer of physical obstacles (houses) and land's slop cost layer and the proper cost values were assigned to these classes.

\subsection{Prototype Results and Discussion}

Figure 7 shows the results of running the model for $25,50,75$ and 100 iterations. 


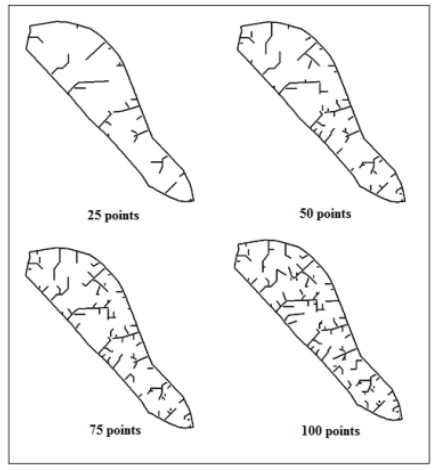

Figure 7. Result of Simulation for Different Runs of Prototype Model

The total network length and fractal dimension of the simulated local roads in the area were calculated for each run of the prototype model and these values were compared with respective values for the transport infrastructure in the reality (Figure 8, Table 2).
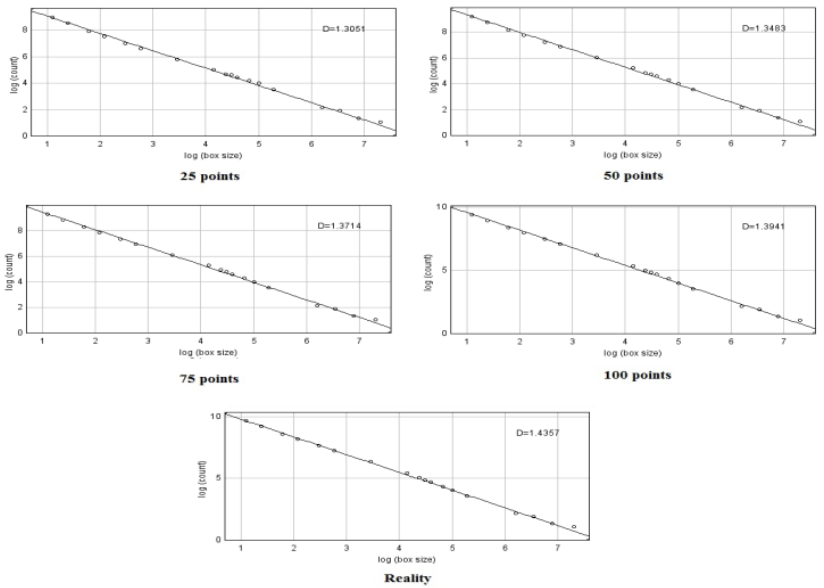

Figure 8. Fractal Dimension Values for Informal Transport Infrastructure Network (Simulation Runs and Reality)

\begin{tabular}{|l|l|l|l|}
\hline & $\begin{array}{c}\text { Total Length } \\
\text { of Informal } \\
\text { Transport } \\
\text { Infrastructure } \\
\text { Network (m) }\end{array}$ & $\begin{array}{c}\text { Fractal } \\
\text { Dimension }\end{array}$ & $\begin{array}{c}\text { Informal } \\
\text { Transport } \\
\text { Infrastructure } \\
\text { Density } \\
(\mathbf{m} / \mathbf{m} 2)\end{array}$ \\
\hline 25 Points & 1089.7 & 1.305 & 0.008 \\
\hline 50 Points & 1816.8 & 1.348 & 0.014 \\
\hline 75 Points & 2261.2 & 1.371 & 0.017 \\
\hline 100 Points & 2802.6 & 1.394 & 0.021 \\
\hline $\begin{array}{l}\text { 496 } \\
\text { Houses } \\
\text { Reality) }\end{array}$ & 6216.5 & 1.435 & \\
\hline
\end{tabular}

Table 2. Total Length of Informal Transport Infrastructure Network, Fractal Dimension, Informal Transport Infrastructure Density Values for the Case Study (Simulation Runs and Reality)

As it was mentioned before, the developed prototype model suffered from a robust housing model and do not consider the different physical, social and economical factors that affect the formation of informal settlement. However, it can be observed that the general structure of emergent pattern of simulation is similar to the pattern of the local road network in the reality.
Also, a rising trend is observable in the total network length, fractal dimension values and informal transport infrastructure density in the simulation results when the number of points (simulated houses) is approaching to the number of the houses in the reality. Therefore, generally it could be stated that the proposed indirect dynamic for modelling of the informal growth of infrastructure has a valid mechanism and the relevant emergent patterns in informal transport infrastructure might be reproduced and explained based on this dynamic.

\section{CONCLUSIONS}

In this study, the morphology and spatial pattern of different types of informal settlement have been reviewed and categorized to clearly define and formulate the mechanism of informal transport infrastructure formation in the context of informal settlement for the first time. Based on this study, two dynamics have been suggested for modelling of the informal transport infrastructure growth phenomenon. In the first suggested dynamic, the infrastructure is extended directly as the result of consolidation of the physical signs of dwellers' movement on the environment because of the frequent usage of the formed track in the environment over time. In the second proposed dynamic that is the main focus of this study, the informal infrastructure growth could be considered as the function of settlement construction dynamic in the settlement. In this term, informal transport infrastructure is extended based on an indirect dynamic by consideration of the void spaces by dwellers as the accessibility corridors in the settlement during the construction process of the settlement. In this study, a simple conceptual model was developed to study the validity of the second proposed dynamic for modelling of the indirect growth of informal transport infrastructure. The result of this model showed that the indirect dynamic can reproduce the respected emergent pattern in the informal infrastructure and the emergent pattern can be explained by this dynamic. However, more studies will be needed in future to define the sub-systems, driving forces and mechanisms of the proposed dynamics clearly for more realistic modelling of the growth process in informal transport infrastructure in the context of informal settlement.

\section{REFERENCES}

Augustijn-Beckers, E.-W., Flacke, J., \& Retsios, B., 2011. Simulating informal settlement growth in Dar es Salaam, Tanzania: An agent-based housing model. Computers, Environment and Urban Systems, 35(2), 93-103.

\section{CONDER., 2002. CD Produtos Informs.}

Fernandez, R. F., 2011. Physical and Spatial Characteristics of Slum Territories Vulnerable to Natural Disasters. Les Cahiers de l'Afrique de l'Est, 44.

Goldstone, R. L., \& Roberts, M. E. 2006. Self-organized trail systems in groups of humans. Complexity, 11(6), 43-50.

Helbing, D., Keltsch, J., \& Molnar, P., 1997. Modelling the evolution of human trail systems. Nature, 388(6637), 47-50.

Huang, A., \& Levinson, D., 2009. Modeling phase changes of road networks: University of Minnesota: Nexus Research Group.

Iqbal, A., 2009. Development of agent based modelling and simulation for informal settlements. ITC, Enschede. 
Kuilman, M., 2011.Quadralectic Architecture - A Panoramic Review, Falcon Press

Matos Mar, J., 1977. Las barriadas de Lima 1957. Lima: Instituto de Estudios Peruanos

Rapoport, A., 1988. Spontaneous settlements as vernacular design. Spontaneous shelter: International perspectives and prospects, 51-77.

Sietchiping, R., 2005. Prospective slum policies: Conceptualization and implementation of a proposed informal settlement growth model. Paper presented at the third urban research symposium on "Land Development, Urban Policy And Poverty Reduction”, Brasilia, Brazil.

Sliuzas, R., 2004. Managing informal settlements, a study using geo-information in Dar es Salaam. Utrecht University and ITC, Utrecht and Enschede, the Netherlands.

Sliuzas, R. V., 1988. Problems in monitoring the growth of a squatter settlement: the housing process in Manzese, Dar es Salaam. ITC, Enschede, the Netherlands.

Sobreira, F., \& Gomes, M., 2001. The Geometry of Slums: boundaries, packing and diversity (No. 1467-1298): Centre for Advanced Spatial Analysis (UCL): London, UK. .

Vahidi, H., 2010. Using agent based simulation to model informal growth of infrastructure. University of Twente, Enschede, the Netherlands.

Yamins, D., Rasmussen, S., \& Fogel, D., 2003. Growing Urban Roads. Networks and Spatial Economics, 3(1), 69-85. 